\title{
Editors' Message Hydrogeological activities in Japan
}

\author{
Yasuo Sakura, Former Associate Editor \\ Chanyuan Tang, Associate Editor
}

Historically, Japan, with its high annual precipitation, relied on surface water to supply the principal domestic, agricultural, and industrial needs. But, since World War II, with the pressing need to increase food production for the expanding population and to support the rapid industrialization and urbanization of the 1960-1980s, groundwater has become a vital part of the nation's water supply. However, excessive groundwater extraction has caused serious problems, such as a marked decline in groundwater levels, land subsidence, and salt-water intrusion into fresh-water aquifers, and many groundwater studies have been implemented to address those problems. In addition, since 1980, studies have also focused on groundwater pollution by organic chemicals from electronic industries; on flow in deep aquifers, as related to nuclear waste disposal; on contamination by nitrogen products from fertilizer usage in agriculture; and pollution from landfills. To study these problems, numerous observation wells have been drilled to provide data that lead to greater understanding of the heterogeneity of aquifers and of groundwater flow.

A special problem is presented in the construction of underground buildings at depths of more than $50 \mathrm{~m}$ as part of the expansion of subway systems, such as in Tokyo. In the 1970s, to alleviate problems of land subsidence, restrictions on groundwater extraction were implemented that have resulted in a remarkable recovery of formerly deep water tables. In turn, this rise in water tables has necessitated preventive measures to address rebound in underground facilities due to the buoyancy effect.

Received, May 2000

Accepted, July 2000

Yasuo Sakura (-)

Department of Earth Sciences, Faculty of Science,

Chiba University, 1-33 Yayoi-cho, Inage-ku,

Chiba 263-8522, Japan

Fax: +81-43-290-2859

e-mail: ysakura@earth.s.chiba-u.ac.jp

Chanyuan Tang

Graduate School of Science and Technology, Chiba University,

1-33 Yoyoi-cho, Inage-ku, Chiba 263-8522 Japan

Hydrogeology Journal (2000) 8:355

The Environment Agency of Japan sets policy regarding the groundwater environment for the country, but in addition, through its office of Official Development Assistance, it assists underdeveloped countries in the exploration and development of their groundwater resources. The agency also serves as an information center on the groundwater of various countries, especially in Asia and Africa.

Trends in academic groundwater research in Japan center on such aspects as groundwater exploration technology, pumping techniques, the theory of fluid flow between salt water and fresh water, the theory of consolidation of subsurface geologic strata, and the theory of mass and heat transport. In addition, supercomputers have facilitated research in among other things, numerical simulation technology of groundwater flow and in the study of heat and mass transport.

The principal organizations in Japan that deal with various aspects of groundwater investigations are the Japanese Association of Groundwater Hydrology, the Japanese Association of Hydrological Sciences, the Japanese Geotechnical Society, and the Japanese Society of Engineering Geology. The numbers of these organizations represent varied scientific, engineering, and agricultural disciplines. In the Japanese Association of Groundwater Hydrology, for instance, of the 900 members, 400 are graduates in the sciences, 300 in engineering, and 200 in agriculture. As to their present positions, 100 are employed by universities, 600 are in consulting, and 200 work for local and national governmental organizations. Thus hydrogeologists in Japan play important roles in addressing challenges to the groundwater environment posed by the increasingly urban Japanese society.

Key words Japan $\cdot$ editorial $\cdot$ general hydrogeology

(C) Springer-Verlag 